\title{
In vivo accuracy of conventional and digital radiographic methods in confirming root canal working length determination by Root ZX
}

Fernando Accorsi OROSCO'1, Norberti BERNARDINELI'², Roberto Brandão GARCIA ${ }^{3}$, Clovis Monteiro BRAMANTE², Marco Antonio Húngaro DUARTE ${ }^{3}$, Ivaldo Gomes de MORAES ${ }^{2}$

\author{
1- DDS, MSc, PhD in Endodontics, Department of Operative Dentistry, Endodontics and Dental Materials, Bauru School of Dentistry, University of São Paulo, \\ Bauru, SP, Brazil. \\ 2- DDS, MSc, PhD, Full Professor of Endodontics, Department of Operative Dentistry, Endodontics and Dental Materials, Bauru School of Dentistry, University \\ of São Paulo, Bauru, SP, Brazil. \\ 3- DDS, MSc, PhD, Associate Professor of Endodontics, Department of Operative Dentistry, Endodontics and Dental Materials, Bauru School of Dentistry, \\ University of São Paulo, Bauru, SP, Brazil.
}

Corresponding address: Fernando Accorsi Orosco - Faculdade de Odontologia de Bauru - USP - Departamento de Dentística, Endodontia e Materiais Odontológicos - Al. Octávio Pinheiro Brisolla, 9-75 - Vila Universitária - 17012-901 - Bauru - SP - Brasil - Phone: 55 (14) $3235-8344$ - Fax: 55 (14) $3224-2788$ - e-mail: faorosco@usp.br

Received: November 07, 2010 - Modification: August 04, 2011 - Accepted: August 25, 2011

\section{ABSTRACT}

$\mathrm{O}$ bjectives: To compare, in vivo, the accuracy of conventional and digital radiographic methods in determining root canal working length. Material and Methods: Twenty-five maxillary incisor or canine teeth from 22 patients were used in this study. Considering the preoperative radiographs as the baseline, a $25 \mathrm{~K}$ file was inserted into the root canal to the point where the Root ZX electronic apex locator indicated the APEX measurement in the screen. From this measurement, $1 \mathrm{~mm}$ was subtracted for positioning the file. The radiographic measurements were made using a digital sensor (Digora 1.51) or conventional type-E films, size 2, following the paralleling technique, to determine the distance of the file tip and the radiographic apex. Results: The Student " $\mathrm{t}$ " test indicated mean distances of $1.11 \mathrm{~mm}$ to conventional and $1.20 \mathrm{~mm}$ for the digital method and indicated a significant statistical difference $(p<0.05)$. Conclusions: The conventional radiographic method was found to be superior to the digital one in determining the working length of the root canal.

Key words: Radiography. Odontometry.

\section{INTRODUCTION}

One of the main difficulties during endodontic treatment is to establish the root canal working length. Theoretically, this point would have to be the apical constriction. Clinically, however, identifying the apical constriction is a challenge, for it presents wide anatomical variations in the apical third of the root canal ${ }^{14}$.

Preparation and filling should end $1 \mathrm{~mm}$ coronal to the radiographic apex of the root. The conventional radiographic method is traditionally used to determine the root canal working length. During this process, the distance between the tip of the file inserted in the root canal and the tip of the radiographic apex is measured. Based on this measurement the full working length can be estimated $7,12,13,16$. However, the conventional radiographic method presents some inconveniences, like the overlapping of anatomical structures and mainly the position of the apical foramen in relation to the apex, which in most cases does not coincide ${ }^{13}$, and the film-processing time.

The digital radiographic method produces images using a sensor instead of radiographic film. The digital x-ray has some advantages over the conventional method, mainly a speedier image acquisition, a much lower radiation dose and image editing ability to more clearly study the details ${ }^{9,19}$.

Nevertheless, the literature is not conclusive on whether the digital radiographic method is more efficient than the conventional radiographic method for root canal working length determination. Thus, the objective of this study was to compare the 
accuracy of the conventional and digital radiographic methods in determining root canal working length.

\section{MATERIAL AND METHODS}

The study was approved by the Institutional Review Board of Bauru School of Dentistry. Twentyfive single-rooted maxillary incisors and canines requiring root canal treatment from 22 patients of a private dental office were used. In this study were used teeth with vital pulp (prosthetic indication) and with pulp necrosis without apical radiolucency. When a preoperative radiography indicated the presence of apical radiolucency, the tooth was treated but not included in the study. Besides, according to Ebrahim, et al. ${ }^{8}$ (2006), the Root ZX is highly accurate in the presence of blood and sodium hypochlorite. However, we tried to eliminate the vital tissues from the canal walls performing the instrumentation of the cervical and medium thirds of the root canal before determination of the working length with the apex locator. All patients had their endodontic treatment completed at the end of the research. After the clinical examination, a preoperative conventional radiography was taken using radiographic film positioners (Cone Indicator - Indusbello Indústria de Instrumentos Odontológicos Ltda, Londrina, PR, Brazil) to prevent or to minimize possible image distortions and the initial measurement of each tooth was done with a millimeter ruler. The following surgical sequence was adopted in all cases: anesthesia, absolute isolation, access opening, pulp extirpation (vital tooth) and instrumentation of the cervical and medium thirds of the root canal, up to about $4 \mathrm{~mm}$ coronal to the radiographic apex; all the canals were irrigated with $1 \%$ sodium hypochlorite at each instrument change.

Considering the preoperative radiographs as baseline, a size $25 \mathrm{~K}$-file was connected to the electronic apex locator Root ZX (J. Morita, Kyoto, Japan) and inserted into the root canal to the point where the device indicated the APEX measurement on the screen. From this measurement, $1 \mathrm{~mm}$ was subtracted for positioning the file. The measurements collected using the Root ZX were made by the same operator. The Digora system (Orion Corporation Soredex, Helsinki, Finland) was used to obtain the digital images for this study. Digora uses a photostimulable phosphor imaging plate $(35 \times 45 \times 1.6 \mathrm{~mm})$, containing an active area of $30 \times 40 \mathrm{~mm}$, equivalent to a size 2 dental $x$-ray film. The Digora radiographs were taken using an x-ray machine (Spectro II, Dabi Atlante, Ribeirão Preto, SP, Brazil) at $10 \mathrm{~mA}$ and $60 \mathrm{kVp}$ with 0.2 $s$ exposure time. All digital and conventional radiographs were obtained by the parallelism technique with the aid of a device to maintain the same position of film and sensor. The file and the Digora sensor were held by a radiographic filmholder especially developed for endodontic use (Endodontic Positioner RH Indusbello; Indusbello Indústria de Instrumentos Odontológicos Ltda), which kept the film and sensor always in the same position. This custom-made film-holder is a new biting device with greater height than the conventional film-holders, whose purpose is to compensate for the part of the cable file or guttapercha cone that are out of the tooth crown during preparation and filling procedures. It means that file or cone/crown set would have the same height of the device, increasing the stability of the position in the mouth. The digital images were transferred to a computer and the distance between the file tip and the radiographic apex was measured using the Digora system. This procedure was performed by three independent examiners (endodontists), using the same computer screen. Brightness/contrast adjustment was freely performed on the Digora.

After the sensitization of the digital sensor, the conventional radiographs were obtained with size 2, type E radiographic films (Ektaspeed, Kodak Company, Rochester, NY, USA), under the same conditions except for an exposure of $0.5 \mathrm{~s}$. (Figure $1 \mathrm{~A}$ and $1 \mathrm{~B})$. Radiographic processing was performed with developer and fixing solutions for radiographic
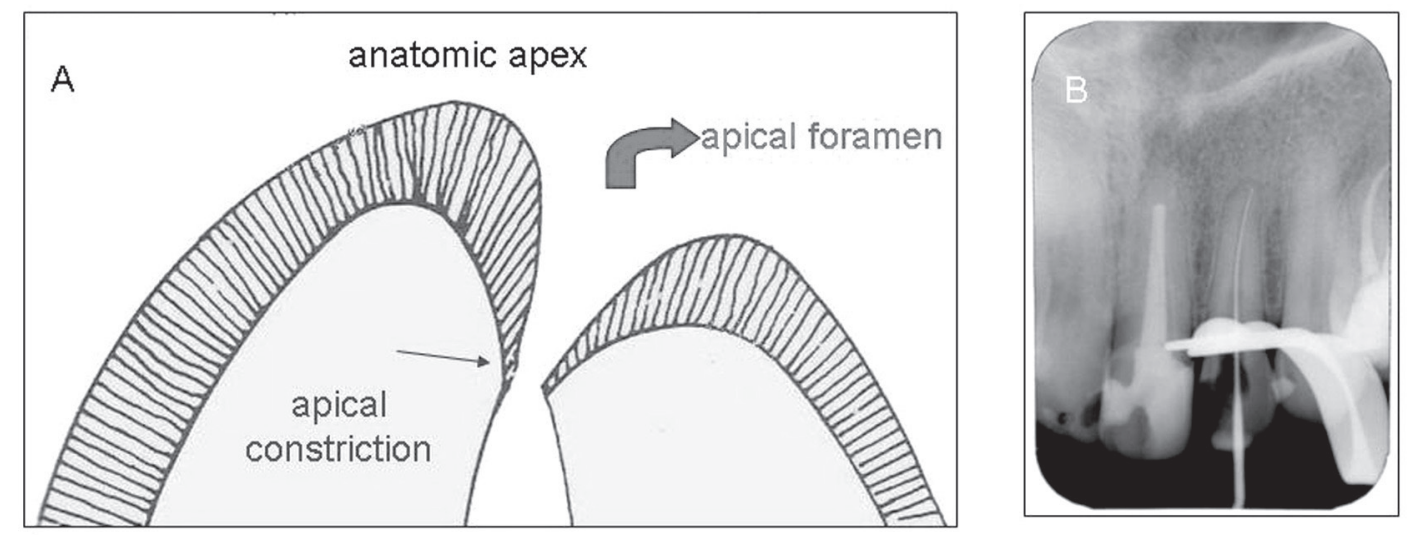

Figure 1-A: Detail of the anatomy of the apical third; B: Conventional radiograph of root canal working length determination 
films (Kodak Company) using the time/temperature method. The conventional images were analyzed by three independent examiners (endodontists) with a magnifying lens $(x 4)$ and a millimeter ruler to measure the distance between the file tip and the radiographic apex. The Kappa test was performed to verify agreement of the measurements among the three examiners. The arithmetic means of the three examiners were used for the statistical analysis for comparison between the methods, using the Student's " $t$ " test with a significance level of $5 \%$.

\section{RESULTS}

The means and standard deviation in $\mathrm{mm}$ of the distance between the file tip and tooth apex for the conventional and digital radiographic methods were $1.116000( \pm 0.089814)$ and 1.208000 $( \pm 0.111504)$, respectively. The Student's " $t$ " test showed a significant difference between the methods $(p<0.05)$.

\section{DISCUSSION}

The Root ZX electronic apex locator was used in this study because it presents higher precision and reliability in the measurements ${ }^{3,5}$. However, it is important to emphasize that this device indicates the location of the apical foramen, which in most cases does not coincide with the apex. Nonetheless, after root canal working length determination using an apex locator many dentists take a conventional or a digital radiograph to confirm the measurement.

The results of this study showed that the conventional radiographic method was better in determining the working length when compared with the digital radiographic method. Such results disagree with those from other studies $2,6,15,17$. According to Schmitd, et al. ${ }^{18}$ (2008), when higher values are recorded using the Digora, it can often be related to the high accuracy of the software in determining the working length, as well as because the image can be enlarged when analyzed on the computer screen.

According to Schmitd, et al. ${ }^{18}$ (2008), the limitation of the conventional radiographic method lies in the dentist's ability to interpret the images; therefore, large variations may arise from one to another professional if a previous calibration is not done. However, Akdeniz and Sogur ${ }^{1}$ (2005), reported that the Digora system was superior to the conventional radiographic method only when the brightness and contrast in the software were used. The authors reported that the use of conventional film type also presented better results relative to the images obtained for type $\mathrm{F}$ films and Digora when the level of the filling material and its homogeneity were evaluated ${ }^{1}$.
Friedlander, et al. ${ }^{10}$ (2002) suggested that only when the resources available in the Digora system are used, a better visualization of the file tip in the interior of the root canal be achieved. Moreover, similar results were obtained in studies ${ }^{4,11}$ that had evaluated the root canal length or alterations in the periapical bone using different digital systems and the conventional method.

Although authors like Schmitd, et al. ${ }^{18}$ (2008) considered that the possibility of image manipulation using the resources offered for the Digora system and other digital systems had an advantage over the conventional method, namely the adjustment of low-quality images that would avoid repetitions and consequently reduce exposing the patient to radiation. Akdeniz and Sogur ${ }^{1}$ (2005) affirmed that standardized procedures were not yet available and compared the adjustments allowed by the digital systems in relation to the image brightness and contrast; therefore, variations between one system and another one could appear. Therefore, it would be necessary to establish first such procedures by comparative studies between the digital systems, in a way to determine the effect of the alterations of brightness and contrast offered by the digital systems on the interpretation of the images for the dentists. Another important factor to be considered is the positioning of the conventional film and the digital sensor. The sensor is not as flexible as the conventional film, often making it difficult to position the patient correctly for the radiograph.

Although the results showed a significant difference between the methods, conventional radiography indicated a shorter distance between the file tip and the tooth apex. Considering this, the clinical difference found was not sufficient to indicate an inaccurate measurement because the difference was less than $2 \mathrm{~mm}$ from the apex in both methods, keeping it at the acceptable radiographic limit between 0.5 and $2 \mathrm{~mm}^{2,3,5}$.

\section{CONCLUSION}

The results of this study showed that the conventional radiographic method was superior to the digital radiographic method in determining root canal working length. Before proceeding with future studies to compare the radiographic methods, it is necessary first to standardize digital radiography, mainly for brightness and contrast, so that the results can be as close as possible to the clinical reality. 


\section{REFERENCES}

1- Akdeniz BG, Soğur E. An ex vivo comparison of conventional and digital radiography for perceived image quality of root fillings. Int Endod J. 2005;38:397-401.

2- Almenar Garcóa A, Forner Navarro L, Ubet Castelló V, Miñana Laliga R. Evaluation of a digital radiography to estimate working length. J Endod. 1997;23:363-5.

3- Bernardes RA, Duarte MAH, Vasconcelos BC, Moraes IG, Bernardineli N, Garcia RB, et al. Evaluation of precision of length determination with 3 electronic apex locators: Root ZX, Elements Diagnostic Unit and Apex Locator, and RomiAPEX D-30. Oral Surg Oral Med Oral Pathol Oral Radiol Endod. 2007;104:e91-4.

4- Borg E, Attaelmanan A, Gröndahl HG. Subjective image quality of solid-state and photostimulable phosphor systems for digita intraoral radiography. Dentomaxillofac Radiol. 2000;29:70-5.

5- Camargo EJ, Ordinola-Zapata R, Medeiros PL, Bramante CM, Bernardineli N, Garcia RB, et al. Influence of preflaring on the accuracy of length determination with four electronic apex locators. J Endod. 2009;35:1300-2.

6- Cederberg RA, Tydwell E, Frederiksen NL, Benson BW. Endodontic working length assessment: comparison of storage phosphor digital imaging and radiographic film. Oral Surg Oral Med Oral Pathol Oral Radiol Endod. 1998;85:325-8.

7- Cohen S, Hargreaves MK. Pathways of the pulp. St. Louis: Mosby Elsevier; 2006. p. 108-17, 254-6.

8- Ebrahim AK, Yoshioka T, Kobayashi C, Suda H. The effects of file size, sodium hypochlorite and blood on the accuracy of Root ZX apex locator in enlarged root canals: an in vitro study. Aust Dent J. 2006;51:153-7.

9- Ellingsen MA, Harrington GW, Hollender LG. Radiovisiography versus conventional radiography for detection of small instruments in endodontic length determination. Part 1. In vitro evaluation. J Endod. 1995;21:326-31.
10- Friedlander LT, Love RM, Chandler NP. A comparison of phosphor-plate digital images with conventional radiographs for the perceived clarity of fine endodontic files and periapical lesions. Oral Surg Oral Med Oral Pathol Oral Radiol Endod. 2002;93:321-7. 11- Huda W, Rill LN, Benn DK, Pettigrew JC. Comparison of a photostimulable phosphor system with film for dental radiology. Oral Surg Oral Med Oral Pathol Oral Radiol Endod. 1997;83:72531

12- Kim-Park MA, Baughan LW, Hartwell GR. Working length determination in palatal roots of maxillary molars. J Endod. 2003;29:58-61.

13- Krajczár K, Marada G, Gyulai G, Tóth V. Comparison of radiographic and electronical working length determination on palatal and mesio-buccal root canals of extracted upper molars. Oral Surg Oral Med Oral Pathol Oral Radiol Endod. 2008;106:e90-3. 14- Kuttler Y. Microscopic investigation of root apexes. J Am Dent Assoc. 1955;50:544-52.

15- Loushine RJ, Weller RN, Kimbrough WF, Potter BJ. Measurement of endodontic file lengths: calibrated versus uncalibrated digital images. J Endod. 2001;27:779-81.

16- Pratten DH, McDonald NJ. Comparison of radiographic and electronic working lengths. J Endod. 1996;22:173-6.

17- Sanderink GCH, Huiskens R, van der Stelt PF, Welander US, Stheeman $\mathrm{E}$. Image quality of direct intraoral $\mathrm{x}$-ray sensors in assessing root canal length. The Radio VisioGraphy, Visualix/VIXA, Sens-A-Ray, and Flash Dent systems compared with Ektaspeed films. Oral Surg Oral Med Oral Pathol. 1994;78:125-32.

18- Schmitd LB, Lima TC, Chinellato LE, Bramante CM, Garcia RB, Moraes IG, et al. Comparison of radiographic measurements obtained with conventional and indirect digital imaging during endodontic treatment. J Appl Oral Sci. 2008;16:167-70.

19- Shearer AC, Horner K, Wilson NHF. Radiovisiography for imaging root canals: an in vitro comparison with conventional radiography. Quintessence Int. 1990;21:789-94. 